\section{Helping children on the autism spectrum deal with hospital admissions}

\author{
Carol Povey
}

For anyone, undergoing surgery is stressful. For children on the autism spectrum, it can be even more traumatic.

Sensory differences are present in the majority of children on the autism spectrum, ${ }^{1}$ and an increasing number of first person accounts illustrate the effects those sensory differences have on autistic people's everyday functioning. ${ }^{2}$ The National Autistic Society recently launched a public awareness campaign, Too Much Information, to raise awareness of the fact that apparently challenging behaviours seen in autistic children may be a result of sensory overload rather than 'bad' behaviour (http:// www.autism.org.uk).

Many autistic people also struggle in unfamiliar environments and situations, and thrive when uncertainty is kept to a minimum. Strategies to support autistic people often involve communicating clearly, and providing structure and a low arousal environment. ${ }^{3}$

There is now an increasing understanding of how best to support children in school, home, and in the community, yet there is little in the literature on how to utilise this understanding in different settings such as in a hospital, and specifically, how to support those children who undergo surgical procedures.

The review by Koski et $a l^{4}$ illustrates this scarcity of evidence. Yet, it also shows that some hospital teams have developed creative approaches to minimising the distress experienced by autistic children in these unfamiliar and often traumatic

Correspondence to Carol Povey, Centre for Autism, The National Autistic Society, 393 City Road, London EC1V 1NG, UK; carol.povey@nas.org.uk situations. Some of the strategies described in the papers reviewed, such as social stories ${ }^{5}$ and augmentative and alternative communication systems, ${ }^{6}$ are used extensively in classrooms or at home. It would certainly be useful to see the use of these strategies, with which many young autistic people and their families are familiar, used more extensively in hospitals, and to see their use fully evaluated.

The importance of listening to and involving caregivers is brought out in this review. Information on how the child reacts in different situations, those things that give them comfort or distress, will help hospital staff to fully individualise their approach.

Some hospitals have made good progress in adapting their procedures to be able to support autistic children with learning disabilities. Macclesfield General Hospital in the UK has achieved The National Autistic Society's Autism Accreditation award, for which the hospital is required to evidence that autism knowledge and understanding informs practice across the hospital. Some acute hospitals now employ acute liaison nurses to help staff support people with learning disabilities, and one children's hospital in the UK has employed a consultant nurse (learning disabilities) with experience and expertise in autism. Hospital passports are in use in a number of settings, which detail the individual's preferred communication methods, and other adaptations that will help the person to cope in a stressful and unfamiliar environment. ${ }^{7}$ There are also helpful resources such as Beyond Words books, which can help hospital staff to communicate with patients, and are recommended by the Royal College of Psychiatrists.

It is important that these different strategies are evaluated, and knowledge shared across hospitals, in order to understand how best to support young children on the autism spectrum in hospital settings, and in particular, children undergoing surgical procedures. This review is an important step in ensuring that not only are all hospitals able to adapt to include every patient, but to make sure what they do is evidence-based.

Twitter Follow Carol Povey at @carolpoveyNAS

Competing interests None declared.

Provenance and peer review Commissioned; internally peer reviewed.

To cite Povey C. Arch Dis Child 2016;101:1081.

Received 12 July 2016

Accepted 24 July 2016

Published Online First 19 August 2016

\section{S Linked}

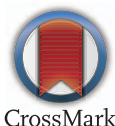

http://dx.doi.org/10.1136/archdischild-2016-310814

Arch Dis Child 2016;101:1081.

doi:10.1136/archdischild-2016-311299

\section{REFERENCES}

1 O'Neill M, Jones RSP. Sensory-perceptual abnormalities in autism: a case for more research? J Autism Dev Disord 1997;27:283-93.

2 Grandin T. Emergence, labeled autistic. Academic Therapy Pubns, 1986.

3 Beadle-Brown J, Roberts R, Mills R. Person-centred approaches to supporting children and adults with autism spectrum disorders. Tizard Learn Disabil Rev 2009; 14:18-26.

4 Koski S, Gabriels RL, Beresford C. Interventions for paediatric surgery patients with comorbid autism spectrum disorder: a systematic literature review. Arch Dis Child 2016;101:1090-4.

5 Gray CA, Garand JD. Social stories: improving responses of students with autism with accurate social information. Focus Autistic Behav 1993:8:1-10.

6 Mirenda P. Autism, augmentative communication, and assistive technology what do we really know? Focus Autism Other Dev Disabil 2001;16:141-51.

7 Brodrick D, Lewis D, Worth A, et al. One-page patient passport for people with learning disabilities. Nurs Stand 2011;25:35-40. 